\title{
LA VERDAD TOMADA EN SERIO ${ }^{1}$
}

\section{THE TRUTH TAKEN SERIOUSLY}

Sergio Chiarloni

Professor da Università degli Studi di Torino, Italia. Email: sergio.chiarloni@unito.it

RESUMEN: El artículo trata de la temática relativa al estudio de los avances en materia de pruebas en el proceso civil, basándose esencialmente en la obra de Michele Taruffo.

PALABRAS-CLAVE: Pruebas; proceso civil; Michele Taruffo; derecho comparado.

SUMMARY: The article deals with the subject of the study of advances in the field of evidence in civil proceedings, based essentially on the work of Michele Taruffo.

KEYWORDS: Testing; civil proceedings; Michele Taruffo; comparative law.

SUMARIO: 1. La verificación judicial de los hechos en la historia. - 2. Verdad, proceso, decisión y narraciones. - 3. Los ordenamientos de common law: ¿procedimientos antiepistémicos? - 4. Casi una conclusión.

\section{LA VERIFICACIÓN JUDICIAL DE LOS HECHOS EN LA HISTORIA}

Junto a muchos méritos, los humanistas del Cuatrocientos y del Quinientos son responsables del arraigo de un prejuicio incluso hasta hoy consolidado en el imaginario colectivo. Han contribuido a difundir la idea de un Medioevo como un conjunto de siglos oscuros, a causa de una deformada perspectiva que los llevaba a volcar hacia atrás los desastres de un reciente pasado: las guerras, las pestilencias, las carestías que atormentaran a Europa en el $1300^{2}$.

\footnotetext{
${ }^{1}$ Artigo recebido em 01/06/2018, sob dispensa de revisão.

${ }^{2}$ Cfr., Sergi, L'idea di Medioevo tra senso comune e pratica storica, Roma, 1998, p. 12 y ss.
} 
Revista Eletrônica de Direito Processual - REDP.

Rio de Janeiro. Ano 12. Volume 19. Número 2. Maio a Agosto de 2018

Periódico Quadrimestral da Pós-Graduação Stricto Sensu em Direito Processual da UERJ

Patrono: José Carlos Barbosa Moreira (in mem.). ISSN 1982-7636. pp. 184-199

www.redp.uerj.br

Los históricos presentan hoy un cuadro muy diverso. Como sugiere Giuseppe

Sergi, el lugar que unifica a las múltiples experiencias que separan la caída del imperio romano y el descubrimiento de América es la experimentalidad.

Un periodo en que no se cree "fideísticamente" en la ratio naturalis, pero tampoco exclusivamente en lo mágico ${ }^{3}$ se debe agrupar en los diversos aspectos que contribuyen a hacer del Medioevo un laboratorio, un marco "en que es posible observar hombres y estructuras en un juego abierto, complejo y fascinante".

Una nítida confirmación de esta complejidad, para el caso particular, pero socialmente más relevante que la reconstrucción de los hechos en el proceso judicial, la encontramos en el primer capítulo de Michele Taruffo, que representa la summa de un compromiso de más de cuarenta años del más autorizado estudioso ${ }^{4}$ entre los pocos italianos que se han dedicado a un campo exigente como el derecho de las pruebas civiles. Gracias a una riquísima documentación, vemos aquí el pasado romano conservado e interpretado por obra de un dominante grupo germánico que no renuncia a las propias tradiciones: desmintiendo una creencia comúnmente difundida, las pruebas "racionales" - testimonio y documentos- conviven en los siglos con las pruebas “irracionales", de mágica fecundación - ordalías y duelo judicial ${ }^{5}$.

Al mismo tiempo, sobre el material recogido se enciende inevitable el faro de las elecciones valorativas. Por siempre orientadas, en el análisis del presente en que hasta ahora se ha dedicado, sobre todo, Taruffo, a sostener, con iluminista confianza, que la llamada verdad procesal debe tender a coincidir con la llamada verdad histórica o material. No sin que nuestro autor reconozca (y a menudo critique) los múltiples vínculos "contra epistémicos" que el juez debe respetar en la actividad dirigida a formar el propio convencimiento. Aquí estamos, entonces, para descubrir, ya en el derecho

\footnotetext{
${ }^{3}$ Que continúa teniendo una gran relevancia social hasta bien adentro de la edad moderna: basta pensar en la característica maravillosa y sagrada de la realeza en Francia e Inglaterra que se manifestaba en el poder curador de los reyes. Cfr. Bloch, I re taumaturghi, trad. it., Turín, 1973.

${ }^{4}$ Junto a Franco Cordero para el proceso penal. Cfr. Tre studi sulle prove penali, Milán, 1963 y, desde el punto de vista del análisis histórico, Riti e sapienza del diritto, Bari, 1981.

${ }^{5}$ Vale la pena recordar que, en el proceso penal, tenemos ejemplos en el siglo XVII del uso de métodos irracionales de formación de la prueba, utilizables, y no examinables por el Juez. De un tipo de prueba, es decir que los cadáveres de los asesinados sangren, si son puestos en presencia de los culpables de su muerte, se ocupó, entre otros Aprosio en su La Grillaia, Génova, 1673, al cap. XII, p. 143, s. Titulado "si a la presencia de los Micidiarij las heridas de los occisos voten sangre". El autor cita dos casos delictuosos en el territorio de Ventimiglia, uno ocurrido en 1620, otro en el 1654: ambos "revelados" a través del sistema probatorio. Taruffo nos recuerda, por otro lado, en La semplice verità, p. 8, que la ordalía constituye una técnica residual, empleada cuando los medios racionales de prueba no llegaban a resolver las dudas sobre los hechos.
} 
Revista Eletrônica de Direito Processual - REDP.

Rio de Janeiro. Ano 12. Volume 19. Número 2. Maio a Agosto de 2018

Periódico Quadrimestral da Pós-Graduação Stricto Sensu em Direito Processual da UERJ

Patrono: José Carlos Barbosa Moreira (in mem.). ISSN 1982-7636. pp. 184-199

www.redp.uerj.br

probatorio lombardo y luego en el carolingio, la emersión de una búsqueda objetiva de la verdad. Siglos antes del 1215, año bisagra para una indagación dirigida también à rebours, y elegido como título del capítulo por el valor simbólico de tres desiguales eventos entonces verificados: la prohibición por parte de la Iglesia de leer y enseñar la Física y la Metafísica de Aristóteles, la prohibición de las ordalías en el Concilio IV de Letrán, la concesión de la Magna Charta Libertatum en Inglaterra.

Luego, el autor nos muestra cómo la evolución en sentido racional de las pruebas se consolida en los siglos sucesivos, sobre todo donde el desarrollo económico y financiero es acentuado, como en Italia y en las Flandes, lugares de partida de una revolución jurídica representada por el triunfo en edad comunal del jus mercatorum, derecho de clase que se emancipa de las duras críticas de los complicadísimos formalismos y de las inenarrables lentitudes del proceso ordinario de derecho común. A cuyo propósito se puede agregar que los privilegios procesales para los grupos sociales emergentes, comerciantes, banqueros y artesanos, arriban inclusive a una suerte de solve et repete procesal, gracias al desarrollo en el bajo Medioevo de una particular utilización de la prueba documental, que da ingreso a la ejecución forzada a través de la emanación de un praeceptum, cuando el solicitante presente al juez cualquier escrito representativo de un crédito líquido (documentos garantizados, letras de cambio e incluso, en los primeros tiempos, simples escrituras privadas).

Naturalmente Taruffo no ignora las relevantes diferencias en las disciplinas ${ }^{6}$. La enorme complejidad de las experiencias medievales se manifiesta en el ámbito de la administración de la justicia no sólo con el extraordinario fraccionamiento y entrevero de los poderes judiciales, sino también a través de las tortuosidades de los procedimientos ordinarios de derecho común ${ }^{7}$.

Quizá se podría desear algunas palabras más sobre la justicia señorial, donde se manifiesta precisamente en materia de pruebas un particular reflejo de las desigualdades sociales típicas de la sociedad feudal. Aludo a la llamada tarificación del testimonio, una

\footnotetext{
${ }^{6}$ Me refiero al parágrafo dedicado entre otros a Rabelais (en La semplice verità, p. 99 y ss.), donde los pasajes del tercer libro sobre los encuentros de Pantagruele con la justicia francesa representada por el juez Bridoye (un topos muy gustosamente frecuentado por nuestros procesalistas) son, sin embargo, recordados con el diverso objetivo de ironizar, justamente, sobre las modernas visiones ritualistas del proceso. Aunque siento no compartir la preocupación de un gran filósofo liberal estadounidense como John Rawls (pero para justificar lo que asevero debería afrontar un largo discurso sobre su teoría procedimental de la justicia y no es este el lugar).

${ }^{7}$ Cfr. el capítulo dedicado a las justicias en Bloch, La società feudale, trad. it., Turín, 1967, p. 405 y ss.
} 
Revista Eletrônica de Direito Processual - REDP.

Rio de Janeiro. Ano 12. Volume 19. Número 2. Maio a Agosto de 2018

Periódico Quadrimestral da Pós-Graduação Stricto Sensu em Direito Processual da UERJ

Patrono: José Carlos Barbosa Moreira (in mem.). ISSN 1982-7636. pp. 184-199

www.redp.uerj.br

serie de reglas de prueba legal que les atribuyen valores diferentes según que la declaración provenga de eclesiásticos, de nobles, o de burgueses y que incapacita a los siervos $^{8}$. Me parece poder decir que las reglas de esta matriz tienen una fuerte valía "contraepistémica" tal de contradecir a aquella "concepción racionalista de la relación entre pruebas y hechos", que caracteriza, como escribe el autor ${ }^{9}$, a la evolución medieval del derecho continental de la pruebas: pero, agregaría yo, la caracteriza sólo en parte (incluso bajo este perfil y no sólo para la supervivencia de las ordalías).

Con referencia a la evolución divergente del derecho inglés, el autor concentra la atención sobre el jurado. A su parecer, desde que se perfilan características del instituto que transforman en juez del hecho a un colectivo de testigos, miembros de la pequeña comunidad a la que pertenecen las partes en juicio, se asiste al nacimiento de "un mito" y de una "salvaguardia de la libertad" ${ }^{10}$ con respecto al poder, que explica su actual perdurar en los ordenamientos de common law, aunque, para los juicios civiles, sólo en los Estados Unidos ${ }^{11}$. A pesar de que el propio jurado, observa el autor, constituya uno de los factores por los que los procedimientos de aquellos ordenamientos serían netamente anticognitivos, "fundados sobre la idea que descubrir la verdad real no tiene particular interés" a diferencia de los sistemas continentales, que concebirían el accertamento de la verdad de los hechos "como uno de los objetivos principales del proceso".

Reservo para después un análisis crítico a esta convicción, compartida por tiempo, es necesario reconocerlo desde ahora, por grandes y autorizados sectores de la doctrina norteamericana ${ }^{12}$. En efecto, se trata, del punto de partida para un filo rojo que atraviesa la entera monografía, alienando poco a poco factores posteriores ${ }^{13}$.

\footnotetext{
${ }^{8}$ Por ejemplo, en las Constituciones sículas (I, 76) encontramos que un burgués valía dos rústicos, un guerrero dos burgueses, un barón dos guerreros, un conde dos barones; situación que se reflejaba también en la fe de atribuirles la palabra en juicio: la palabra del conde valía hasta 100 Augustali, la del barón 50, etc.

${ }^{9}$ La semplice verità, p. 26.

${ }^{10}$ La semplice verità, p. 24.

${ }^{11}$ Ya no muchos, sin embargo, a causa de los costos muy elevados que son afrontados por las partes que quieren valerse del jurado.

12 Además del mismo Taruffo, desde una importante obra juvenil, Il processo civile "adversary" nell'esperienza americana, Padua, 1979.

${ }^{13}$ Como confirmación de la tendencia de cada uno a ver en los libros que lee lo que más le interesa recuerdo que Cavallone, In difesa della veriphobia (Considerazioni amichevolmente polemiche su un libro recente di Michele Taruffo), en Riv. dir. proc., 2010, p. 19, asevera que en el libro en mención "la comparación no es desarrollada tanto entre diversos ordenamientos históricos y/o vigentes, sino entre los distin-tos posibles aspectos de cualquier disciplina jurídica de la instrucción probatoria”.
} 


\section{VERDAD, PROCESO, DECISIÓN Y NARRACIONES}

Los posteriores capítulos representan el núcleo fuerte de la obra, y son fruto de un admirable armazón teórico-filosófico, que no es manifestación de pereza erudita, sino virtud indispensable para el estudioso del derecho probatorio. Basta pensar en la importancia de las distinciones entre verdad y certeza, verdad y verosimilitud ${ }^{14}$, verdad y probabilidad, verdad y su justificación, trazadas todas con extremo brillo.

El autor, no se prolonga sobre el tema, viejo de milenios, de si el conocimiento y la verdad son posibles. Muy oportunamente, recorta aquel tema lo necesario para sus fines: para refutar con decisión las teorías irracionalistas del postmodernismo, adhiriéndose, en cambio, a las perspectivas del racionalismo crítico, que en el mismo tiempo asevera la cognoscibilidad del mundo externo y reconoce la eventualidad del error. Adaptándolo, luego, al caso particular en que se trata de reconstruir eventos que no son más reales, porque pertenecen al pasado y son inductivamente reconstruidos con los medios a disposición ${ }^{15}$. En efecto, la justicia de Estado se manifiesta como justicia procedimental imperfecta, porque no existe un método, por cuanto meticuloso, capaz de garantizar un resultado "justo", esto es, que corresponda al criterio de verdad en la reconstrucción de los hechos. Pero, se trata de un resultado - si se quiere, transcendente - que es, sin embargo, perseguido.

\footnotetext{
Aprovecho la ocasión para decir que esta larga e interesantísima recensión me confirma la convicción que a menudo las polémicas científicas en el campo del derecho, provocadas por una diversidad de aproximaciones metodológicas y por un contraste sobre los valores de referencia, no comportan necesariamente contra-posición en las tesis finales. Bruno Cavallone no es un verifóbico postmoderno e irracionalista. Es un fino estudioso del juicio de hecho, que en cierto punto escribe (p. 12) que los jueces deben decidir "sobre la base de pruebas idóneas para la verificación de las alegaciones fácticas de las partes, bajo el criterio tanto de las reglas del proceso como de criterios epistemológicos sensatos, comprensibles y coherentes con nuestra cultura". Conclusión, de ello estoy seguro, perfectamente compartible por el común amigo autor del "libro reciente".

${ }^{14}$ A propósito de la definición estipulativa de verosimilitud, por la que es verosímil "lo que corresponde al id quod plerumque accidit" (La semplice verità, p. 88 y s.) encuentro que el jurista debería poner otra: siempre con un latinismo llamaría también verosímiles los hechos verificados "prima facie" como consecuencia de sumarias informaciones que conduzcan a la decisión positiva sobre el llamado fumus boni juris. Se trata de los contextos de justificación provisorios, que con-sienten la emanación de los proveimientos cautelares y que habrían consentido la emanación del auto de acogimiento en el procedimiento sumario según las líneas diseñadas en el proyecto Mastella de la precedente legislatura.

${ }^{15}$ Aunque, más que con el histórico el juez iría en ocasiones comparado con el geógrafo o con el explorador, debiendo ocuparse de controversias sobre situaciones de la realidad directamente cognoscibles. Piénsese en las muchas controversias en materia de servidumbre o aquellas relativas al respeto de las distancias legales.
} 
Revista Eletrônica de Direito Processual - REDP.

Rio de Janeiro. Ano 12. Volume 19. Número 2. Maio a Agosto de 2018

Periódico Quadrimestral da Pós-Graduação Stricto Sensu em Direito Processual da UERJ

Patrono: José Carlos Barbosa Moreira (in mem.). ISSN 1982-7636. pp. 184-199

www.redp.uerj.br

Esto es, se trata de acreditar un modelo de proceso que refute las reglas antiepistémicas que no son justificadas por la preeminencia de valores superiores respecto a la consecución de lo verdadero. Y aquí el autor se compromete tanto al criticar disciplinas vigentes, como al proponer interpretaciones coherentes con las elecciones de fondo. Basta aquí recordar la condena de la supervivencia de medios de prueba legales en nuestro ordenamiento ${ }^{16}$ y la interpretación de la reciente regla sobre la no contestación, introducida con el texto modificado por la ley 69/2009, como simple inversión de la carga de la prueba, de modo que, la emersión en el curso del proceso de la no verdad de los hechos no contestados deba ser tenida en cuenta por el juez ${ }^{17}$.

En el último capítulo, dedicado a "decidir la verdad", muchas páginas afrontan las cargas probatorias. El autor es desconfiado con respecto al ejercicio de poderes discrecionales del juez en la distribución de estas cargas, en violación del art. 2697 cód. civ. Comparto, pero no del todo. El art. 2697 norma de aparente claridad es a menudo de dificilísima interpretación. En el sentido que, con frecuencia, no existe un criterio conceptual seguro para atribuir a un hecho la calificación de constitutivo, o bien por el contrario la calificación de impeditivo. En estos casos, más que frecuentes, la distribución de la carga no puede sino ocurrir según juicios de valor (poner la carga de probar el hecho que más raramente se verifica, como en la pareja capacidad-incapacidad en materia contractual, o bien poner la carga a la parte que tiene más facilidad de probar, como en la pareja existencia-inexistencia de la justa causa de despido, según la orientación predominante en la jurisprudencia de mérito antes que el dilema fuese resuelto por la intervención del legislador).

El capítulo dedicado a las narraciones procesales es interesante por el doble registro oportunamente seguido por el autor. Se vale de los fragmentos usables que se pueden divisar en las teorizaciones de los narradores contemporáneos. Combate las

\footnotetext{
${ }^{16}$ Ninguna duda en lo que concierne a la eficacia de prueba legal de la confesión. Por lo que concierne al juramento se puede observar que su utilización, rarísima y, como en las ordalías, sólo a falta de otros medios de prueba, puede haber, paradójicamente, un notable valor epistémico, si se lo compara con la alterna-tiva de aplicar la regla de juicio de la carga de la prueba. Me refiero a los casos en que es instado en las litis bagatelarias, por la probabilidad que el adversario considere que no vale la pena jurar en falso, o bien en los casos en que la parte que lo insta posee un documento de su buen derecho pero prefiere no producirlo por razones fiscales.

${ }^{17}$ La semplice verità, p. 130 y ss. Sin embargo, no comparto la aserción que el hecho no contestado tiene el $50 \%$ de ser falso. Aparte la opinión que en otro lugar (p. 92) el autor objeta justamente el hábito de cuantificar en términos matemáticos la probabilidad de haberse verificado un hecho, es necesario advertir que, en la normal dialéctica de los litigios, la falta de contestación de un hecho favorable al adversario implica una fuerte probabilidad que aquel hecho sea cierto.
} 
Revista Eletrônica de Direito Processual - REDP.

Rio de Janeiro. Ano 12. Volume 19. Número 2. Maio a Agosto de 2018

Periódico Quadrimestral da Pós-Graduação Stricto Sensu em Direito Processual da UERJ

Patrono: José Carlos Barbosa Moreira (in mem.). ISSN 1982-7636. pp. 184-199

www.redp.uerj.br

dudas irracionales a las que estos escritores arriban cuando se ocupan del derecho. Se puede ciertamente ver el proceso como un conjunto de narraciones de los sujetos que en él interactúan: de los abogados, de las partes, de los testigos, del juez. Pero no se puede pretender valorar exclusivamente en base a criterios internos, como una narración literaria. Una narración procesal puede ser buena. Pero, la valoración de aquella final debe ser conducida esencialmente con el registro de lo verdadero. Y el racionalista crítico, que refuta el escepticismo de quien piensa inalcanzable la verdad, no hace coincidir los dos atributos: ni lo convence que el único criterio de valoración de justicia de una sentencia en la reconstrucción de los hechos sería la coherencia interna de su motivación (la narración buena) y no la corrección epistémica del procedimiento de valoración de las pruebas (la narración verdadera). Corrección valorable, agrego, incluso con referencia a los veredictos, en base a un análisis de la historia del proceso por obra de sus actores y del público, cuando se hayan interesado en ello.

\section{Los ordenamientos de common law: ¿procedimientos antiepistémicos?}

Ya he señalado que Taruffo se adhiere a un punto de vista difundido en la doctrina norteamericana, completamente teorizada en dos libro de Damaska y sintetizada en el primero como oposición entre proceso como actuación de elecciones políticas y proceso como solución de $\operatorname{conflictos}^{18}$. Aquí parece obtenerse una tensión conceptual entre cultura jurídica originaria y cultura jurídica adoptiva de este autor ${ }^{19}$. Pero con referencia al primer término de la dicotomía podemos legítimamente pensar, más que en un Estado que se vale del proceso para imponer su dirección política, en un Estado donde el proceso tiende a la actuación de la ley sustancial -obviamente fruto de elecciones políticas $-\mathrm{y}$, por tanto, a su aplicación a hechos correctamente reconstruidos ${ }^{20}$.

Que en los ordenamientos de common law las controversias sean con gran frecuencia resueltas sin ningún reparo a una solución orientada a la verificación de los hechos es ciertamente verdadero. Basta pensar en la enorme difusión de formas de justicia negociada. Más precisamente, para el proceso penal, en el plea bargaining (de

\footnotetext{
${ }^{18}$ I volti della giustizia e del potere. Analisi comparativa del processo, trad. it., Boloña, 1991, p. 158 y s.; Il diritto delle prove alla deriva, trad. it., Boloña, 2003, p. 109 y ss.

${ }^{19} \mathrm{La}$ del bloqueo soviético (ha sido profesor de derecho en la Universidad de Zagreb) con la estadounidense (desde 1971 vive en los Estados Unidos, donde es profesor de derecho comparado en la Law School de Yale).

${ }^{20}$ Cfr., a propósito, Ferrua, Il “giusto processo”, 2a ed., Boloña, 2007, p. 79.
} 
Revista Eletrônica de Direito Processual - REDP.

Rio de Janeiro. Ano 12. Volume 19. Número 2. Maio a Agosto de 2018

Periódico Quadrimestral da Pós-Graduação Stricto Sensu em Direito Processual da UERJ

Patrono: José Carlos Barbosa Moreira (in mem.). ISSN 1982-7636. pp. 184-199

www.redp.uerj.br

amplitud muy superior a nuestra negociación) y, para el proceso civil, en los sistemas alternativos de resolución de disputas y, sobre todo, en la circunstancia que la extragrande mayoría de las controversias regularmente iniciadas ante un juez no concluyen con una sentencia, sino con una conciliación o una transacción procurada por los abogados de las partes ${ }^{21}$, por una serie de razones donde asume preeminencia el costo excesivo de la defensa (pero también, creo yo, la sabia reflexión sobre los resultados instructorios del pretrial).

Las cosas se complican, sin embargo, si volvemos la mirada a las disciplinas procesales y a su resultado con una decisión. Los factores puestos en el campo por la doctrina crítica y muy bien desarrollados por Taruffo en varios lugares del libro son esencialmente tres: la presencia del jurado, la estructura del proceso adversary, la falta (más bien, la falta de ejercicio) de poderes directivos del juez (y, en particular, de poderes instructorios) obstaculizarían la justicia en cuestión de los proveimientos.

Con referencia al jurado, es realmente permisible advertir perplejidades. Es cierto que el veredicto sin motivación le hace asumir un rasgo oracular. Es cierto que una correcta valoración de las indagaciones de expert witnesses sometidos a la cross examination puede resultar imposible. Muy cierto que sobre los resultado de ciertos procesos se esconde - más que para los jueces profesionales que, como quiera que sea, no están exentos - el peligro del perjuicio, quizá manchado de racismo, como ha demostrado la experiencia de un no lejano pasado. Sin embargo, muchos de los duros ataques que son lanzados contra el instituto están preñados de un cierto aristocratismo profesional-académico. Como si la compacta comunidad de los juristas (abogados que se vuelven jueces, profesores que son abogados o esperan nominaciones en las jurisdicciones superiores) percibiese las formas de participación popular en la administración de justicia ${ }^{22}$ bajo el criterio de un cuerpo extraño (casi una amenaza barbárica) de la cual es necesario liberarse.

Con respecto a los peligros que amenazan la corrección en la apreciación de las pruebas por parte de un instituto garantizado por la octava y novena enmienda de la

\footnotetext{
${ }^{21}$ Damaska, Op. ult. cit., p. 203.

${ }^{22}$ Formas a las que continuo mirando con favor. V. Chiarloni y Scaparone P., Riforma dell'ordinamento giudiziario e partecipazione popolare all'amministrazione della giustizia, en AA.VV., La riforma dell'ordinamento giudiziario e i problemi della giustizia, Vol. II, Roma, 1977, p. 157 y ss.
} 
Revista Eletrônica de Direito Processual - REDP.

Rio de Janeiro. Ano 12. Volume 19. Número 2. Maio a Agosto de 2018

Periódico Quadrimestral da Pós-Graduação Stricto Sensu em Direito Processual da UERJ

Patrono: José Carlos Barbosa Moreira (in mem.). ISSN 1982-7636. pp. 184-199

www.redp.uerj.br

Constitución americana ${ }^{23}$ existen remedios, ciertamente mejorables. Basta pensar en la

influencia ejercitada por el actuar del juez, que se expresa no sólo en las importantes instrucciones finales. Un obrar esencial incluso al controlar los eventuales excesos de los defensores. Lo que vale con particular atención a la agresividad al conducir la cross examination, en violación de los deberes de candor con respecto al juez y al acusador público, por lo demás, agresividad por considerar no de manera frecuente, vista la apenas señalada pertenencia de todos al mismo círculo profesional. En cuanto a las dificultades para ciudadanos no expertos en comprender los duelos entre los consultores técnicos, se recuerda que -al menos según una línea reconstructiva de la reciente epistemología - la credibilidad de cualquier discurso científico depende de su traducibilidad en los términos del lenguaje común, que iría fomentada. En cuanto al peligro que la decisión esté contaminada de prejuicio, ayuda el fatigoso proceso de elección de jurados. Permanece el veredicto no motivado. Ciertamente, es innegable la fundamental importancia de la motivación para los ordenamientos de derecho continental $^{24}$.

Garantizada por el art. 111, sexto párrafo de nuestra Constitución, porque permite el control democrático de la justicia de las decisiones, además de una más fácil individualización de las razones sobre las cuales fundar los motivos para un eventual gravamen $^{25}$. Sin embargo, no creo que ella tenga que ver con la corrección de solución de las cuestiones de hecho. La motivación de los proveimientos representa la racionalización analítica y a posteriori del dispositivo, como es demostrado por la estructura de la fase decisoria en el proceso penal y en el proceso laboral. El comando jurisdiccional es, por tanto, siempre ${ }^{26}$ examinado como consecuencia de una

\footnotetext{
${ }^{23}$ Vale la pena recordar que incluso antes los iluministas continentales se habían pronunciado por la introducción del jurado en lugar del juez funcionario. Por ejemplo, en 1736 Beccaria, Dei delitti e delle pene, ahora en edición nacional de las obras, Milán, 1984, p. 59; en 1748 Montesquieu, Esprit des lois, XI, 6 (Cfr. trad. it. al cuidado de Sergio Cotta, Turín, reimp. 1973, Vol. I, p. 278).

${ }^{24}$ Cuidadosamente estudiada por Taruffo, en una monografía hasta ahora actual, La motivazione della sentenza civile, Padua, 1975.

${ }_{25}$ Aunque se trata a mi juicio de una garantía renunciable por las partes, bajo el mismo criterio del contradictorio, al menos por cuanto concierne a las sentencias civiles de primer grado, donde podría ser tranquilamente introducida la motivación a solicitud, por escribir en caso de proposición de la impugnación de la parte derrotada. Para la argumentación de esta tesis, cfr. mi voz Giusto processo (diritto processuale civile), en Enc. Dir., Annali, Vol. II, Tomo I, Milán, 2009, p. 403 y ss.

${ }^{26}$ Creo que así ocurre en aquellos procesos, como aquel ante el juez único, donde no es dable obtener una separación cronológica entre un momento de la decisión y momento de la redacción de la motivación. En suma, antes el juez "piensa" el dispositivo y luego se apresta escribir la motivación. La gran diferencia con respecto al proceso penal o al proceso laboral es que aquí el dispositivo toma existencia jurídica junto a la motivación. Lo que permite al juez, aunque, supongo, no muy a menudo, cambiar el dispositivo
} 
Revista Eletrônica de Direito Processual - REDP.

Rio de Janeiro. Ano 12. Volume 19. Número 2. Maio a Agosto de 2018

Periódico Quadrimestral da Pós-Graduação Stricto Sensu em Direito Processual da UERJ

Patrono: José Carlos Barbosa Moreira (in mem.). ISSN 1982-7636. pp. 184-199

www.redp.uerj.br

consideración general y sintética de los resultados de la instructoria (podemos decir "holística", en sentido bueno, a condición que la expresión no quiera aludir a cualquier forma de intuición irracional, como, me parece, es entendida por Taruffo ${ }^{27}$ ). Tampoco podemos sostener que, a menudo, sean más correctamente examinados los dispositivos por los cuales el decisor sabe que se deberá a continuación extender la motivación, casi insinuando una falta de sentido de responsabilidad de los componentes de un jurado.

Finalmente, last but not least, visto que la obra de Taruffo está dedicada al proceso civil, se debe recordar que el recurso al jurado va declinando en este sector y que donde es mantenido (piénsese, por ejemplo, en las class actions) actúa a menudo como un importante factor de democracia económica con respecto a la avaricia de un capitalismo de rapiña, en contextos que son a veces criticados no ya por la incapacidad de juzgar correctamente sobre los hechos, sino por el uso discrecional de la liquidación de los daños punitivos que puede dar lugar a injustificadas disparidades de trato y perjudicar el equilibrio económico de las empresas involucradas, a ventaja, muy a menudo, más de los abogados que de los pertenecientes a la clase ${ }^{28}$.

Con referencia al proceso adversary, también aquí la seriedad de los problemas no es olvidada. Pero, también aquí, no creo que la difcultad para el juez de llegar a la verdad, especialmente para un juez pasivo como el de los países del common law, dependa de la estructura del proceso. Esto es, dependa del hecho que dos opuestas falsedades contadas por los abogados difícilmente permitan reconstruir los hechos de la causa $^{29}$ a un juez no dotado de autónomos poderes instructorios (o culturalmente no apto para ejercitarlos). Los abogados no tienen interés en falsificar la realidad, al menos cuando nos encontramos en presencia de una litis de pretensión contestada ${ }^{30}$, sobre todo

pensado en un primer momento, si la consideración analítica de los hechos lo conduce a una solución diversa respecto a su consideración sintética inmediatamente después de la lectura de las actas y la revocación del escrito.

${ }^{27}$ La semplice verità, p. 64 y s.

${ }^{28}$ Kagan, La giustizia americana, come il contraddittorio fa il diritto, trad. it., Boloña, 2009, p. 211. La obra de este autor contiene una polémica muy violenta contra el sistema de justicia norteamericano del cual se denuncia la frecuente inequidad, incluso recurriendo a ejemplificar sobre la base de muchos casos concretos. Me parece, por otro lado, a pesar del subtítulo, una obra, como frecuentemente ocurre con los críticos de la American exceptionalism, basada sobre factores de contexto extraños al principio del contradictorio considerado per se.

${ }^{29}$ Resumo a grandes rasgos el pensamiento que Taruffo desarrolla, en La semplice verità, p. 46 y ss. y v. también p. 157, con respecto al comportamiento de los abogados en la cross examination.

${ }^{30}$ En las litis de pretensión insatisfecha ocurre que el abogado del demandado niegue los hechos constitutivos o deduzca hechos extintivos o impeditivos inexistentes. Pero se trata de tácticas procesales sólo dirigidas a diferir una condena inevitable, gracias a la necesidad de la instrucción probatoria que de 
Revista Eletrônica de Direito Processual - REDP.

Rio de Janeiro. Ano 12. Volume 19. Número 2. Maio a Agosto de 2018

Periódico Quadrimestral da Pós-Graduação Stricto Sensu em Direito Processual da UERJ

Patrono: José Carlos Barbosa Moreira (in mem.). ISSN 1982-7636. pp. 184-199

www.redp.uerj.br

porque arriesgan así de ser desmentidos por los resultados de la instructoria. Aquí estoy de acuerdo con las bien argumentadas objeciones de Cavallone ${ }^{31}$. Usualmente, los abogados, cuando discuten las cuestiones de hecho, si se trata de good faith disagreements, tienden a convencer al juez de su interpretación de los hechos relevantes, buscando poner a la luz circunstancias favorables, y disminuir la relevancia de las deducidas por el adversario (además, pero no vemos nada de malo, empeñándose en contestar la credibilidad de los testimonios por este último deducidos). La "regla de oro", constitucionalizada por la reciente modificación del art. 11 Const. para nuestro proceso penal, representa el sello de la fuerza epistémica del contradictorio en la formación de la prueba, como se manifiesta precisamente en el examen entrecruzado de los testimonios. "Su fuerza no está en la idea quimérica y platónica que las partes cooperen a un común fin de búsqueda de la verdad...; el presupuesto epistemológico sobre el que se funda es que la verdad se manifieste, es más, se 'contradiga' contra el querer mismo de las partes, precisamente en el conflicto de las perspectivas opuestas" 32 .

Sin embargo, se debe recordar que Taruffo no se limita a contestar (a mi juicio sin persuadir) estas evidencias teóricas. El individualismo competitivo ante el juez al llevar las propias pruebas y controlar las adversarias es, de por sí, favorable a la verificación de la verdad. La facilidad con la que el adversary legalism puede conducir, en la orientación norteamericana, a resultados inicuos en la administración de la justicia precisamente con referencia a aquella verificación depende (yo diría exclusivamente) del contexto, como por otro lado no se cansa de advertir el autor. Aquí entran en juego circunstancias, por otro lado extrañas al modelo y a su disciplina, que terminan con contaminar su funcionamiento. Me limito, por un lado, a recordar el costo desmedido y privado de públicos controles de la asistencia legal, combinado con la absoluta insuficiencia de las medidas de legal aid que determina a menudo posiciones de absoluto desequilibrio entre las partes, vista la fundamental importancia de los defensores en todos los pasajes del procedimiento, comprendida ahí la adquisición de las pruebas. Problema sólo en parte afrontado en Inglaterra, cuyo balance prevé ingentes asignaciones para el legal aid, que sin embargo no ayudan a los grupos medios, cuyos miembros, si están involucrados en un litigio, pueden arriesgar la ruina económica. Son

ella emana, y ciertamente no ponen en dificultad al juez en la reconstrucción de los hechos cuando finalmente arriba el momento de la decisión.

${ }^{31}$ In difesa della veriphobia, cit., p. 6 y ss.

${ }^{32}$ Es difícil decirlo mejor que en este pasaje de Ferrua, op. cit., p. 93. 
Revista Eletrônica de Direito Processual - REDP.

Rio de Janeiro. Ano 12. Volume 19. Número 2. Maio a Agosto de 2018

Periódico Quadrimestral da Pós-Graduação Stricto Sensu em Direito Processual da UERJ

Patrono: José Carlos Barbosa Moreira (in mem.). ISSN 1982-7636. pp. 184-199

www.redp.uerj.br

años ya que un autorizado procesalista inglés insiste en predicar la necesidad de mirar más allá del Canal, beneficiándose bajo este perfil de la German advantage $^{33}$ : tarifas profesionales razonables establecidas por el Estado en lugar de aquellas absurdas practicadas por un monopolio profesional ${ }^{34}$.

Con referencia a la iniciativa instructoria, el juez americano puede asumir pruebas de oficio gracias a la Regla 614 letra A de las Federal Rules of Evidence, según la cual, The court may, on its own motion or at the suggestion of a party, call witnesses, and all parties are entitled to cross-examine witnesses thus called. Y puede, por la misma norma, letra B, interrogate witnesses, whether called by itself or by a party. Taruffo nos informa de la existencia de esta normativa, que parece encarnar el propio método epistémicamente válido por él anhelado ${ }^{35}$. Pero nos dice enseguida que aquel juez no hace casi uso de los poderes que la ley le atribuye por motivos ideológicos y culturales que lo impulsan a no infiltrar elementos inquisitorios al interior del adversary legalism, cuyas desgracias permanecen, por tanto, intactas ${ }^{36}$.

Aquí es necesario agarrar el hilo. Si queremos razonar, como por otro lado hacen todos los críticos del American exceptionalism, más allá de las estructuras normativas e invocar circunstancias de contexto que conciernen al concreto funcionamiento del mecanismo procesal en la vida cotidiana de los foros, debemos entonces comportarnos del mismo modo cuando examinemos los ordenamientos continentales ${ }^{37}$.

Tendremos así modo de darnos cuenta que en uno al menos de estos ordenamientos la verificación de la verdad no aparece "como uno de los objetivos principales del proceso". En el nuestro. Dejamos también perder la circunstancia que,

\footnotetext{
${ }^{33}$ Desde el afortunado título de un ensayo de Langbein, The German Advantage in Civil Procedure, en University of Chicago Law Review, 1985, p. 823 y ss., dirigido a sostener la superioridad de los sistemas continentales de procedimiento respecto a los anglosajones. Para un crítica severa de este ensayo cfr., por otro lado, Allen, Kock, Reichenberg y Rosen, The German Advantage in Civil Procedure: A Plea for Fewer Generalities and Greater Detail in Comparative Law Scholarship, en Northwestern Law Review, 1988, p. 705 y ss. Y v. también Stiefel y Maxeiner, Civil Justice Reform in the United States, Opportunity for Learning from 'Civilized' European Procedure instead of Continued Isolation?, en The American Journal of Comparative Law, 1994, p. 147 y ss.

${ }^{34}$ Cfr. Zuckerman, Lord Woolf's Access to Justice: Plus ça change, en Modern Law Review, 1996, p. 773 y ss.; Id., On Civil Procedure, 2a ed., Oxford, 2003, p. 347 y ss. Y v. también Lord Justice Jackson's Review of Civil Litigation Cost s-Preliminary Report, 2009, p. 435.

${ }^{35}$ Cfr., La semplice verità, p. 160.

${ }^{36}$ La semplice verità, p. 159; cfr. también Damas ka, Il diritto delle prove alla deriva, p. 113.

${ }^{37}$ Para la observación que los análisis comparatísticos que alaban los sistemas continentales de procedimiento evitan observar cómo funcionan en la realidade cfr. Allen y Leiter, Naturalized Epistemology and the Law of Evidence, en Public Law and Legal Theory Papers de la Northwestern University School of Law, 2001, n. 33, p. 26, nota 57, ensayo en gran parte dedicado a la crítica de Posner, An Economic Approach to the Law of Evidence, en Stanford Law Review, 1999, p. 1477 y ss.
} 
Revista Eletrônica de Direito Processual - REDP.

Rio de Janeiro. Ano 12. Volume 19. Número 2. Maio a Agosto de 2018

Periódico Quadrimestral da Pós-Graduação Stricto Sensu em Direito Processual da UERJ

Patrono: José Carlos Barbosa Moreira (in mem.). ISSN 1982-7636. pp. 184-199

www.redp.uerj.br

ignorando (o no llegando a respetar) los comandos de celeridad impartidos por el legislador, el juez se encuentra juzgando sobre los hechos incluso años después de haber asumido las pruebas. ¡Más que one day in court! Me limito a los poderes instructorios y

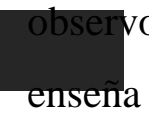
o que, aunque faltan datos estadísticos apartados al respecto, la experiencia enseña que también el juez italiano no ejercita casi nunca aquellos poderes incluso cuando la ley se los atribuye, como en el proceso laboral. Por dos razones. Ante todo, porque nos encontramos frente a poderes subsidiarios (por lo menos, en cuanto al ejercicio sucesivo a él) con respecto a las deducciones de parte al interior del sistema de preclusiones que disciplina la fase introductiva ${ }^{38}$. Ello significa que el juez tendrá oportunidad de introducir pruebas de oficio sólo cuando las deducciones instructorias de las partes (más fácilmente, de una sola entre ellas) sean insuficientes o tardías. Circunstancia no muy frecuente.

Además el juez, empleado civil del Estado, no raramente es prisionero del espíritu burocrático bien descrito por el joven $\operatorname{Marx}^{39}$. Cuando ello ocurre es obvio que, en cambio, en vez de empeñarse en la admisión de los medios prueba no deducidos por la parte negligente, él preferirá hacer, sin más, aplicación de la regla de juicio sobre la carga de la prueba ${ }^{40}$. Por la misma razón, si es también cierto que, de acuerdo al art. 253 c.p.c., "el juez interroga al testigo sobre los hechos en torno a los cuales está llamado a testificar", es igualmente cierto que a menudo él se limita a la lectura de los capítulos preparados por las partes. Cuando no ocurra algo peor y ni siquiera asista a la declaración y a la respectiva puesta en discusión por obra de los abogados.

Regreso brevemente a las disciplinas procesales para recordar que en los ordenamientos de common law existen institutos que expresan, para el proceso civil ${ }^{41}$, una vocación hacia la verdad que no es posible encontrar en el nuestro: la disciplina del

\footnotetext{
${ }^{38}$ Taruffo, Poteri probatori delle parti e del giudice in Europa, en esta revista, 2006, p. 468, vuelve oportunamente evidente la función "integradora y supletoria" de la iniciativa del juez respecto a la iniciativa de parte.

${ }^{39}$ Critica della filosofia hegeliana del diritto pubblico, en Marx-Engels, Opere scelte, Roma, 1969, p. 22 y ss.

${ }^{40}$ Sin que ello comporte un vicio de la sentencia denunciable con la impugnación. Estoy firmemente convencido, a pesar de algunas oscilaciones en nuestra jurisprudencia, que el poder de asumir pruebas de oficio es un poder discrecional, por las razones ya indicadas en Giuristi dell'Est e giuristi dell'Ovest a confronto sui fondamentali problemi del processo civile, en esta revista, 1989, p. 282 y ss.

${ }^{41}$ Diversa es la disciplina para el proceso penal, justamente fundamentada en el privilege against self incrimination, a menudo invocado superficialmente, con el recurso al latinismo nemo tenetur edere contra se, para justificar la inexistencia del testimonio de la parte y del correlativo deber de verdad en nuestro ordenamiento, que permite a las partes la más amplia facultad de mentir en el proceso civil, sin soportar ninguna consecuencia negativa.
} 
Revista Eletrônica de Direito Processual - REDP.

Rio de Janeiro. Ano 12. Volume 19. Número 2. Maio a Agosto de 2018

Periódico Quadrimestral da Pós-Graduação Stricto Sensu em Direito Processual da UERJ

Patrono: José Carlos Barbosa Moreira (in mem.). ISSN 1982-7636. pp. 184-199

www.redp.uerj.br

discovery documental, con el conexo duty of disclosure, que obliga a las partes - bajo sanciones que pueden arribar al contempt of court - a brindar a sus adversarios todas las escrituras relevantes aunque desfavorables; la facultad de llamar a las partes al banco de los testigos con la sanción por perjury en caso de falsedad de las declaraciones brindadas (hasta cinco años de prisión en Estados Unidos y hasta siete en Reino Unido); para el ordenamiento inglés el deber de verdad de las declaraciones rendidas en los actos introductorios sancionado por las recientes Civil Procedure Rules (siempre bajo pena de contempt $)^{42}$.

\section{Casi una conclusión}

Hay razones extraprocesales y en parte extrajurídicas que me han inducido a contestar, quizá con armas despuntadas, el punto de vista difundido que ve en los ordenamientos de common law diseñar procedimientos judiciales dirigidos exclusivamente a la solución de los conflictos y, por tanto, indiferentes a la verificación de la verdad. Dejo correr la antigua e ilustre tradición que ve a escritores ingleses y americanos sobresalir en el estudio del derecho probatorio, que constituye, entre otras cosas, un sector autónomo de los estudios ${ }^{43}$. Encuentro el estímulo para concluir en el bellísimo parágrafo del libro de Taruffo intitulado al valor social de la verdad ${ }^{44}$, porque precisamente de aquí veo emerger un oxímoron de muy difícil justificación. Sabemos bien que el amor por la verdad es mucho más intenso en la sociedad y en la cultura anglosajona. Más que en el continente, al menos en el Sur. Así en la política, donde las falsificaciones propagandísticas no son toleradas y hacen caer en desgracia a quien busca acreditarlas, a diferencia del populismo charlatán que tantos desastres ha ocasionado en la historia del continente; en la religión, que ve contrapuesto el rigor protestante a la indulgencia católica y a la inclinación al compromiso de sus exponentes;

\footnotetext{
42 Ulteriores profundizaciones en mi Riflessioni microcomparative su ideologie processual $e$ accertamento della verità, en esta revista, 2009, numero especial Due Iceberg a confronto: le derive di common law $e$ civil law, p. 101 y ss.

${ }^{43}$ Me limito a recordar a los precursores: Gilbert, The Law of Evidence, Dublin, 1754, que inicia con una larga citación del Essay Concerning Human Understanting, obra capital de un padre del empirismo moderno y del iluminismo crítico como John Locke y los tres fundamentales volúmenes de Bentham, Rationale of Judicial Evidence, bajo el cuidado de J. Mill, Londres, 1827. Sobre la formulación racionalista de los estudiosos ingleses, v. Twining, The Rationalist Tradition of Evidence Scholarship, en Well and Truly Tried, Essays on Evidence in Honour of Sir Richard Eggleston, Sidney, 1982, p. 215.

${ }^{44}$ La semplice verità, p. 92 y ss.
} 
Revista Eletrônica de Direito Processual - REDP.

Rio de Janeiro. Ano 12. Volume 19. Número 2. Maio a Agosto de 2018

Periódico Quadrimestral da Pós-Graduação Stricto Sensu em Direito Processual da UERJ

Patrono: José Carlos Barbosa Moreira (in mem.). ISSN 1982-7636. pp. 184-199

www.redp.uerj.br

en la filosofía donde la tradición del racionalismo empirista y la precisión del análisis del lenguaje son evidenciados en la comparación entre analíticos y continentales, con estos últimos en el rol de alfiles del postmodernismo racionalista. Pero, entonces me pregunto:

¿Es posible que en un ambiente semejante sobreviva un sistema judicial que de acuerdo a sus críticos estaría estructurado de modo tal que resulta no apto para verificar la verdad de los hechos sometidos al juicio?

\section{REFERENCIAS BIBLIOGRAFICAS}

Allen y Leiter, Naturalized Epistemology and the Law of Evidence, en Public Law and Legal Theory Papers de la Northwestern University School of Law, 2001.

Allen, Kock, Reichenberg y Rosen, The German Advantage in Civil Procedure: A Plea for Fewer Generalities and Greater Detail in Comparative Law Scholarship, en Northwestern Law Review, 1988.

Aprosio, La Grillaia, Génova, 1673.

Beccaria, Dei delitti e delle pene, ahora en edición nacional de las obras, Milán, 1984.

Bentham, Rationale of Judicial Evidence, bajo el cuidado de J. Mill, Londres, 1827.

Bloch, I re taumaturghi, trad. it., Turín, 1973.

Bloch, La società feudale, trad. it., Turín, 1967.

Cavallone, In difesa della veriphobia (Considerazioni amichevolmente polemiche su un libro recente di Michele Taruffo), en Riv. dir. proc., 2010.

Chiarloni y Scaparone P., Riforma dell'ordinamento giudiziario e partecipazione popolare all'amministrazione della giustizia, en AA.VV., La riforma dell'ordinamento giudiziario e i problemi della giustizia, Vol. II, Roma, 1977.

Chiarloni, Giuristi dell'Est e giuristi dell'Ovest a confronto sui fondamentali problemi del processo civile, en esta revista, 1989.

Giusto processo (diritto processuale civile), en Enc. Dir., Annali, Vol. II, Tomo I, Milán, 2009.

, Riflessioni microcomparative su ideologie processual e accertamento della verità, en esta revista, 2009, numero especial Due Iceberg a confronto: le derive di common law $e$ civil law.

Cordero, Riti e sapienza del diritto, Bari, 1981. 
Revista Eletrônica de Direito Processual - REDP.

Rio de Janeiro. Ano 12. Volume 19. Número 2. Maio a Agosto de 2018

Periódico Quadrimestral da Pós-Graduação Stricto Sensu em Direito Processual da UERJ

Patrono: José Carlos Barbosa Moreira (in mem.). ISSN 1982-7636. pp. 184-199 www.redp.uerj.br

Tre studi sulle prove penali, Milán, 1963.

Critica della filosofia hegeliana del diritto pubblico, en Marx-Engels, Opere scelte, Roma, 1969.

Ferrua, Il "giusto processo", 2a ed., Boloña, 2007.

Gilbert, The Law of Evidence, Dublin, 1754.

Kagan, La giustizia americana, come il contraddittorio fa il diritto, trad. it., Boloña, 2009.

Langbein, The German Advantage in Civil Procedure, en University of Chicago Law Review, 1985.

Montesquieu, Esprit des lois, XI, 6 (Cfr. trad. it. al cuidado de Sergio Cotta, Turín, reimp. 1973, Vol. I.

Posner, An Economic Approach to the Law of Evidence, en Stanford Law Review, 1999.

Sergi, L'idea di Medioevo tra senso comune e pratica storica, Roma, 1998.

Stiefel y Maxeiner, Civil Justice Reform in the United States, Opportunity for Learning from 'Civilized' European Procedure instead of Continued Isolation?, en The American Journal of Comparative Law, 1994.

Taruffo, Il processo civile “adversary” nell'esperienza americana, Padua, 1979. La motivazione della sentenza civile, Padua, 1975. La semplice verità. Bari, 2009.

Twining, The Rationalist Tradition of Evidence Scholarship, en Well and Truly Tried, Essays on Evidence in Honour of Sir Richard Eggleston, Sidney, 1982.

Zuckerman, Lord Justice Jackson's Review of Civil Litigation Costs - Preliminary Report, 2009. Lord Woolf's Access to Justice: Plus ça change, en Modern Law Review, 1996 , On Civil Procedure, 2a ed., Oxford, 2003. 